7 O'Hara MW, Neunaber DJ, Zekoski EM. Prospective study of postpartum depression: prevalence, course and predictive factors. J Abnormal Psychol 1984:93:158-71

8 Green MJ. Who is unhappy after childbirth? Antenatal and intrapartum correlates from a prospective study. J Reprod Infant Psychol 1990:8:175-83.

9 Hobfoll SE, Ritter C, Lavin J, Hulsizer MR, Cameron RP. Depression prevalence and incidence among inner-city pregnant and postpartum prevalence and incidence among inner-city p
women. J Consult Clin Psychol 1995;65:445-53.

10 Cox JL, Connor Y, Kendell RE. Prospective study of the psychiatric disorders of childbirth. Br J Psychiatry 1982;140:111-7.

11 Watson JP, Elliott SA, Rugg AJ, Brough DI. Psychiatric disorder in pregnancy and the first postnatal year. Br J Psychiatry 1984;144:453-62.

12 Pagel MD, Smilkstein G, Regen H, Montano D. Psychosocial influences on new born outcome: a controlled prospective study. Soc Sci Med 1990;30:597-604.

13 Hedegaard M, Henriksen TB, Sabroe S, Secher NJ. Psychological distress in pregnancy and preterm delivery. BMJ 1993;307:234-9.

14 Teixeira JMA, Fisk NM, Glover V. Association between maternal anxiety in pregnancy and increased uterine artery resistance index: cohort based study. BMJ 1999;318:153-7.

15 Cox JL, Holden JM, Sagovsky R. Detection of postnatal depression. Development of the 10-item Edinburgh postnatal depression scale. $\mathrm{Br} \mathrm{J}$ Psychiatry 1987:150:782-6.

16 Crown S, Crisp AH. Manual of the Crown-Crisp experiential index. London: Hodder and Stoughton, 1979.
17 Murray D, Cox JL. Screening for depression during pregnancy with the Edinburgh depression scale (EPDS). J Reprod Infant Psychol 1990;8:99107

18 Thorpe K. A study of the Edinburgh postnatal depression scale for use with parent groups outside the postpartum period. J Reprod Infant Psychol 1993;11:119-25.

19 Green, JM, Snowdon C, Statham H. EPDS by post. Br J Psychiatry $1991 ; 158: 865$

20 Harris B, Othman S, Davies JA, Weppner GJ, Richards CJ, Newcombe RG, et al. Association between postpartum thyroid antibodies and depression. BMJ 1992;305:152-6.

21 Fergusson D, Horwood J, Thorpe K, ALSPAC Study Team. Changes in depression during and following pregnancy. Paediatric Perinatal Epidemiol $1996 ; 10 \cdot 279-93$.

22 Cooper PJ, Murray L. Course and recurrence of postnatal depression. evidence for the specificity of the diagnostic concept. Br J Psychiatry $1995 ; 166: 191-5$

23 Mynors-Wallis LM, Gath DH, Day A, Baker F. Randomised controlled trial of problem solving treatment, antidepressant medication, and combined treatment for major depression in primary care. BMJ 2000;320:26-3.

24 Spinelli MG. Interpersonal psychotherapy for depressed antepartum women: a pilot study. Am J Psychiatry 1997;154:1028-30.

(Accepted 19 April 2001)

\title{
Impact of published clinical outcomes data: case study in NHS hospital trusts
}

\author{
Russell Mannion, Maria Goddard
}

Centre for Health

Economics,

University of York, Heslington, York YO10 5DD

Russell Mannion senior research fellow Maria Goddard assistant director Correspondence to: R Mannion rm15@york.ac.uk

BMJ 2001;323:260-3

\begin{abstract}
Objective To examine the impact of the publication of clinical outcomes data on NHS Trusts in Scotland to inform the development of similar schemes elsewhere.

Design Case studies including semistructured interviews and a review of background statistics. Setting Eight Scottish NHS acute trusts. Participants 48 trust staff comprising chief executives, medical directors, stroke consultants, breast cancer consultants, nurse managers, and junior doctors.
\end{abstract} Main outcome measures Staff views on the benefits and drawbacks of clinical outcome indicators provided by the clinical resource and audit group (CRAG) and perceptions of the impact of these data on clinical practice and continuous improvement of quality.

Results The CRAG indicators had a low profile in the trusts and were rarely cited as informing internal quality improvement or used externally to identify best practice. The indicators were mainly used to support applications for further funding and service development. The poor effect was attributable to a lack of professional belief in the indicators, arising from perceived problems around quality of data and time lag between collection and presentation of data; limited dissemination; weak incentives to take action; a predilection for process rather than outcome indicators; and a belief that informal information is often more useful than quantitative data in the assessment of clinical performance.

Conclusions Those responsible for developing clinical indicator programmes should develop robust datasets. They should also encourage a working environment and incentives such that these data are used to improve continuously.

\section{Introduction}

The public dissemination of standardised data on clinical outcomes is now established practice in many health systems. In the United States, where public reporting is most advanced, comparative information on performance in the form of report cards, provider profiles, and consumer reports has been released for over a decade. ${ }^{1-3}$ In Europe, Scotland has been at the forefront of public disclosure. Since 1994 the Scottish Executive has published clinical outcome indicators collected by the clinical resource and audit group (CRAG) for all Scottish NHS acute trusts and health boards. More recently, clinical performance data have been published for trusts in England and Wales as part of the NHS performance assessment framework.

A postal questionnaire survey conducted by the Scottish Executive in 1997 indicated that the CRAG indicators published in Scotland were of some practical value to health professionals and, in a few instances, had helped to bring about a change in clinical practice. On the whole, however, the survey found that the indicators had little effect on behaviour. ${ }^{4} \mathrm{We}$ present the key findings of a study designed to examine the impact of the publication of these data on provider organisations. The CRAG indicators are similar to those now published more widely within the rest of the United Kingdom, and therefore an analysis of the Scottish experience may help with the implementation of such programmes elsewhere.

The CRAG indicators are compiled and disseminated by the Scottish Executive. Seven reports have been published detailing 38 clinical indicators for named trusts and health boards in Scotland. It is important to note that the CRAG indicators are not part of a formal framework of performance assessment. Since the indicators were first published the 
Scottish Executive has emphasised that they should not be used to make definitive judgments on the performance or quality of services.

The indicators vary by specialty but have some common features:

- They are based on a linked dataset comprising inpatient hospital episode statistics, the 1991 census small area statistics, and recorded deaths

- To minimise the role of random year on year variation each indicator spans a period of at least three years

- The indicators are standardised to control for aspects of case mix that can be identified on the basis of existing data. They are also standardised, when appropriate, for deprivation ${ }^{5}$ or the principal diagnosis of any hospital admissions in the previous five years, or both.

\section{Methods}

\section{Selection and interview strategy}

We considered that the most appropriate methods for explaining in detail the use of the CRAG indicators would be case studies of trusts comprising semistructured interviews with key staff and a review of background documentation. We selected eight trusts, reflecting a range of sizes (income and number of beds), geographical area (city, town, rural), and previous "performance" on the CRAG indicators (table). While the case studies covered the full range of published indicators, for the purposes of obtaining more in depth analysis we focused on two clinical specialties: one published at health board level (five year survival in women with breast cancer) and one published for each trust (30 day survival after emergency admission for stroke).

Interviews were undertaken with chief executives, medical directors, consultants with responsibility for breast cancer services, consultants with responsibility for stroke services, nurse managers, and junior doctors (eight of each). The interviews were semistructured, tape recorded, and transcribed before analysis.

\section{Analysis}

We thought that clinical indicators would be more likely to generate action when the data are perceived to be credible and up to date and when staff believe they are meaningful and important. Similarly, we assumed that action would be more likely to be generated when the external environment facilitates and supports change through strategies such as targeted dissemination, staff training in the use of data, and a framework of incentives.

We analysed interview transcripts using the qualitative methods of content analysis. ${ }^{6}$ After an initial scrutiny of the transcripts we identified several preliminary themes under broad headings to reflect our prior hypotheses. We then collected together passages under each identified theme and cross referenced them according to the site and the type and grade of staff. We also analysed the data to assess whether our findings were related to characteristics of trusts (for example, size, geographical location, and performance on the chosen indicators).

\section{Results}

Impact on behaviour and practice

The CRAG indicators had a "low profile" in all trusts and were rarely cited by staff as the primary drivers of quality improvement or sharing best practice between organisations. In six trusts the CRAG indicators were reported to have stimulated some action in relation to breast cancer or stroke services, but such action was restricted to checking and auditing the quality of the data rather than direct action to improve delivery of service (table).

The indicators were seldom used in isolation when service changes were being considered and were typically augmented with more detailed local data. The main use to which the CRAG data were put was to add further weight and background evidence to applications for additional funding, either within the trust or to the health board. In four trusts the CRAG data were cited as useful background information to support the case for a

Impact of CRAG data on eight NHS hospital trusts (breast cancer and stroke services)

\begin{tabular}{|c|c|c|c|c|c|c|c|}
\hline & \multirow{2}{*}{$\begin{array}{c}1997 \\
\text { income } \\
\text { (£ millions) }\end{array}$} & \multirow{2}{*}{$\begin{array}{l}\text { No of } \\
\text { beds }\end{array}$} & \multirow[b]{2}{*}{ Location } & \multicolumn{2}{|r|}{ Stroke } & \multicolumn{2}{|r|}{ Breast cancer } \\
\hline & & & & Indicator* & Reported impact of indicator & Indicator* & Reported impact of indicator \\
\hline 1 & $<50$ & $<500$ & Town & Worse & $\begin{array}{l}\text { CRAG data stimulated further audit and } \\
\text { introduction of patient protocols. Indicators } \\
\text { used as background information to make } \\
\text { successful case for establishing stroke unit }\end{array}$ & Average & No obvious impact \\
\hline 2 & $>50$ & $>500$ & Town & Average & $\begin{array}{l}\text { Provided background information to support } \\
\text { case for new stroke unit }\end{array}$ & Average & No obvious impact \\
\hline 3 & $>50$ & $>500$ & City & Average & No obvious impact & Average & $\begin{array}{l}\text { CRAG data one of background reasons } \\
\text { why } 0.5 \text { million invested in additional } \\
\text { staff and facilities; one stop clinic set up }\end{array}$ \\
\hline 4 & $>100$ & $>1000$ & Town & Worse & $\begin{array}{l}\text { Data used alongside other relevant } \\
\text { information to argue for new stroke unit; } \\
\text { stimulated audit of data }\end{array}$ & & No reported impact \\
\hline 5 & $>50$ & $>500$ & Town & Average & $\begin{array}{l}\text { CRAG data one of background factors used } \\
\text { successfully to make case for stroke unit; } \\
\text { stimulated data audit }\end{array}$ & Average & $\begin{array}{l}\text { Background factor in setting up of new } \\
\text { breast clinics and increase in } \\
\text { mammography services }\end{array}$ \\
\hline 6 & $>100$ & $>1000$ & City & Average & No obvious impact & Average & $\begin{array}{l}\text { Used as background information to inform } \\
\text { development of services }\end{array}$ \\
\hline 7 & $>50$ & $>500$ & Rural & Average & No obvious impact & Average & No impact \\
\hline 8 & $>50$ & $>500$ & Rural & Average & $\begin{array}{l}\text { No obvious impact on changing stroke } \\
\text { services. Satisfactory performance on CRAG } \\
\text { data used as reason by local health board to } \\
\text { decline additional funding }\end{array}$ & Average & $\begin{array}{l}\text { Interesting background information but not } \\
\text { specifically identified with changing } \\
\text { practice }\end{array}$ \\
\hline
\end{tabular}

${ }^{\star}$ Compared with average for Scotland. 


\section{Reasons for low impact of CRAG indicators \\ Credibility}

"One concern is how valid the data are. It is important if you are going to use data that you have clinical people on board and that they are happy the data collection is correct. We have a degree of suspicion over some of the CRAG data that are coming out" (stroke consultant)

Timeliness

"It's pretty basic information and it comes out several years after it is taken. Things have changed over that period of time. So, in relation to say treatment of cervical cancer, the whole way of cancer management has changed. The change had already occurred by the time the data were issued" (medical director)

\section{Awareness}

"There should be more widespread dissemination of this information [the CRAG reports]. It would certainly be useful to push it down to my level of service manager ... Clinical outcomes don't just apply to doctors" (nurse manager)

\section{Training and facilitation}

"I don't think there is sufficient knowledge about CRAG data. It is not taught in medical schools" (breast surgeon)

\section{Incentives}

"The reward [for performing well on the indicators] is for those services looking for development. It [the CRAG data] is used to help strengthen the case for change. If you are bidding for capital equipment you can use it to persuade your case. In terms of sanctions it is a peer one-not letting your peers down" (chief executive)

Supplementary information

"I don't think at the current level of accuracy you can pull out that sort of information [individual clinical performance] from these figures. Poor performance with doctors tends to be [transmitted] from word of mouth and other soft information" (stroke consultant)

Process versus outcome indicators

"It is easier to measure the process, it is quicker and more responsive than outcome data (breast surgeon)

External accountability

"We are not really held to account at all on this set of indicators" (clinical director)
Training and facilitation - None of the trusts ran specific training or education programmes on the appropriate use and interpretation of clinical indicators, and no single person within each trust was identified as being responsible for supporting their use throughout the organisation.

Incentives-The indicators are not part of a formal system of performance assessment, with an incentive mechanism attached to performance. However, some staff acknowledged that informal incentives that had an effect on status and professional reputation were sometimes associated with relative performance on the indicators.

Supplementary information-Some staff thought that informal information transmitted through channels and professional networks was more useful than formal indicators in capturing important aspects of performance that defy simple codification. In particular, the clinical indicators were often viewed as too unwieldy and out of date to spot poor clinical performance in staff and that "whistle blowing" and "word of mouth" were the most common channels for alerting initial concern.

Process or outcome indicators-Many members of staff preferred process rather than outcome indicators as they were thought to be more reliable, up to date, and easier to measure and to provide better guidance on what specific actions are needed to improve the quality of care.

External accountability-Little pressure was exerted by outside bodies on trusts for them to "perform" well on the CRAG indicators. On the whole, health boards did not hold trusts accountable for their performance, and it was reported that patients or their representatives seldom consulted or acted on the indicators.

\section{Discussion}

Our findings suggest that the CRAG indicators have helped to raise the level of awareness of quality issues among trust staff and in some instances may have alerted providers to specific issues that require further investigation. However, we also found that the indicators were rarely used directly to stimulate continuous quality improvement nor were they used to identify and share best practice between organisations.

Our findings are based on case studies of only eight Scottish trusts and, although the sample was selected to be broadly representative of trusts in Scotland, may not be applicable to trusts elsewhere in the United Kingdom. Similarly, our study focused on the impact of only two clinical indicators, and our findings may have been different if we had focused on other indicators. Notwithstanding the above, as the clinical indicators published under the performance assessment framework in England and Wales are similar to those published in Scotland, many of our findings relating to these data may be directly transferable to similar programmes currently being developed elsewhere in the United Kingdom. We believe that this is the first in depth evaluation of the impact of a clinical indicator programme in a UK context, which makes many of our findings more directly transferable to the rest of the NHS.

There have been a limited number of studies based in the United States that have assessed the impact of 
the publication of clinical data on provider organisations. On the whole, these studies have found that published clinical indicators rarely stimulate quality improvement. ${ }^{1-3} 7$ Our findings indicate several reasons why published clinical indicators often have little or no effect in provider organisations. A key lesson of the Scottish experience is that those responsible for designing clinical indicator systems should not only concentrate on developing robust datasets with but should also encourage a suitable organisational environment and incentive context to foster the use of these data for continuous quality improvement.

We thank the interviewees, who without exception readily gave up their valuable time to share with us their knowledge of the CRAG indicators. We are grateful to Peter Smith and Huw Davies for their comments on an earlier draft of this paper. We also thank David Clyne and Steve Kendrick for their assistance with this project.

Contributors: RM was principal investigator and is guarantor of the paper. RM and MG designed the study. RM conducted the interviews and performed the preliminary qualitative analysis. MG read a sample of interview transcripts and helped to interpret the data. Both authors contributed towards the final paper.

Funding: Department of Health as part of a core programme of work on performance management at the Centre for Health Economics, University of York. The views expressed in this paper are those of the authors and not necessarily those of the Department of Health.

Competing interests: None declared.

1 Marshall M, Shekelle P, Leatherman S, Brook R. Public disclosure of performance data: learning from the US experience. Qual Health Care 2000;9:53-7.

\section{What is already known on this topic}

Current policy on performance assessment in England and Wales places a great deal of emphasis on the collection and dissemination of clinical information

Dissemination of clinical outcome data has had limited impact on the behaviour of provider organisations in the United States

\section{What this paper adds}

Research in Scottish trusts suggests that clinical indicators are rarely used to stimulate quality improvement or share good practice

The reasons for low impact include internal factors relating to the properties of the indicators and external factors within the organisational environment in which the data are used

2 Marshall M, Shekelle P, Leatherman S. Public reporting of performance: lessons from the USA. J Health Serv Res Policy 2000;5:1-2.

3 Marshall M, Shekelle P, Leatherman S, Brook R. What do we expect to gain from the public release of performance data? A review of the evidence. JAMA 2000;283:1866-74.

4 Kendrick S, Cline D, Finlayson A. Clinical outcome indicators in Scotland: lessons and prospects. In: Davies H, Malek M, Nielson A, Tavolaki M, eds. Managing quality and controlling costs. Aldershot: Ashgate Publishing, 1999.

5 Carstairs V, Morris R. Deprivation and health in Scotland. Aberdeen: Aberdeen University, 1991.

6 Banister P, Burman E, Parker I, Taylor M, Tindall C. Qualitative research methods in psychology: a research guide. Buckingham: Open University Press, 1994.

7 Rainwater J, Romano P, Antonius D. The Californian hospital outcome project: how useful is California's report card for quality improvement? Comm J Qual Improv 1999;24:31-9.

(Accepted 13 June 2001)

\section{Declaring financial competing interests: survey of five general medical journals}

Amina Hussain, Richard Smith

Although many authors of biomedical journal articles have financial competing interests, they often fail to disclose them. ${ }^{1-3}$ Editors have been concerned about this for a long time. In 1985, the International Committee of Medical Journal Editors produced a statement on conflicts of interest, and journal editors adopted individual policies. ${ }^{4}$ But how effective have their policies been in practice?

Krimsky et al investigated the financial interests of over 1000 authors whose articles appeared in 14 scientific and medical journals in $1992 .^{3}$ Although $15 \%$ of authors had financial ties relevant to one of their publications, no voluntary disclosures were published. In 1998, Stelfox et al showed that 23/24 authors (96\%) defending the safety of calcium channel antagonists had financial ties with manufacturers of these drugs compared with 11/30 (37\%) who were critical of their use. $^{1}$ Only $2 / 70$ articles disclosed the authors' potential conflicts of interest. These findings confirmed that little had been achieved since initial concerns had been raised over a decade earlier. Recently, however, editors have been paying more attention to the issue and urging authors to declare competing interests. This study aimed to find out whether more authors have been doing this.

\section{Methods and results}

Using random number tables, we selected six sample issues of five leading medical journals (Annals of Internal Medicine, BMJ, JAMA, Lancet, and New England Journal of Medicine) from each of four years: 1989, 1994, 1996, and 1999. All editorials, papers reporting original research, and letters were examined to see if they contained a statement declaring authors' potential financial competing interests (this did not include statements that only mentioned the funding source). We also examined each journal's written policy on financial competing interests (see the BMJ's website).

We studied 3642 articles, 52 (1.4\%) of which declared authors' competing interests: two articles in 1989, eight in 1994, four in 1996, and 38 in 1999. The papers section had the greatest proportion of declarations $(23 / 656 ; 3.5 \%)$, followed by editorials $(7 / 412$; $1.7 \%)$, then letters $(22 / 2574 ; 0.9 \%)$ (table).

\section{Comment}

After much delay, there are now signs of a small, but increasing, proportion of articles declaring competing interests in some journals. Variations in policy require-
$B M J$, London WC1H 9JR

Amina Hussain

Clegg scholar

Richard Smith

editor

Correspondence to: A Hussain,

Raigmore Hospital, Inverness IV2 3UJ hussainamina@

hotmail.com

BMJ 2001;323:263-4

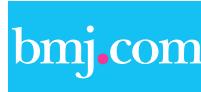

Written policies on each of the five journals are available on the BMJ's website 